\title{
Anesthesia for Patients with Prior Stroke
}

\author{
Hemangi Sanjay Karnik ${ }^{1}$ Ruchi Arunkumar Jain ${ }^{1}$ \\ ${ }^{1}$ Department of Anaesthesiology, Lokmanya Tilak Municipal Medical \\ College and General Hospital, Sion, Mumbai, India
}

\begin{abstract}
Address for correspondence Hemangi Sanjay Karnik, MD, Department of Anaesthesiology, Lokmanya Tilak Municipal Medical College and General Hospital, Sion, Mumbai 400022, Maharashtra, India (e-mail: dr_hemangi@hotmail.com).
\end{abstract}

\begin{abstract}
Keywords

- stroke

- anesthesia

- perioperative risk

- cerebral ischemia

An increasing number of patients with a prior history of stroke present for various types of surgeries. They have varying degree of neurological disability and associated co-morbidities, which pose challenges for their perioperative management. There is paucity in literature about their management guidelines for noncardiac, noncarotid surgeries. The available literature suggests higher risk of perioperative stroke, postoperative neurological deficits, and other morbidities. Measures to reduce perioperative risks are discussed in this review. Prior optimization by improving modifiable risk factors, choosing appropriate timing of elective surgery, and careful titration of anesthesia and close monitoring are needed.
\end{abstract}

\section{Introduction}

Stroke is the second most common cause of death $(11.8 \%$ of all deaths) worldwide and the third most common cause of disability (4.5\%). ${ }^{1}$ About 10 to 11 million people suffer from stroke every year and $50 \%$ of those survive with residual neurologic disability., ${ }^{2,3}$ Advances in acute stroke management have resulted in increased survival with varying degrees of recovery. More than $80 \%$ of the strokes are ischemic type and, hence, are mainly discussed in this review. As majority of patients who suffer from ischemic stroke are older in age, concomitant systemic illnesses are common. However, the incidence of hemorrhagic as well as ischemic stroke is also increasing in younger population. ${ }^{1}$ These patients often present for unrelated surgeries. Pre-existing neurological disability, associated co-morbidities, and effects of anesthesia and surgery make these patients prone to perioperative complications. Aggravation of the neurological disability and occurrence of a secondary stroke in the perioperative period are 6 to 12 times more common in stroke patients than in general population. ${ }^{4,5}$ Perioperative complications can be reduced by carefully planning anesthesia according to the cerebrovascular reserve of the patient and the risks associated with the proposed surgery.

\section{Pathophysiology, Management, and Recovery of Acute Ischemic Stroke}

Interruption of blood supply to an area of brain is a major trigger for ischemic stroke. It may occur due to thrombosis or cerebral embolism. Glucose and oxygen deprivation leads to cell death and neurological dysfunction. Common risk factors for the acute ischemic stroke and their preventive measures are listed in - Table 1..$^{6-8}$ Disabilities following acute stroke include hemiplegia, hemiparesis, focal motor deficits, autonomic, sensory and speech disturbances, comprehension, memory and emotional problems, nutritional derangements, etc. Immediately after an acute ischemic stroke, cerebral autoregulation is impaired often bilaterally for 1 to 3 months, and cerebral perfusion is affected by even minor changes in blood pressure or alteration in position. ${ }^{9-11}$ The vasomotor reactivity is also impaired for approximately 3 months after acute ischemic stroke. ${ }^{12,13}$ This makes stroke patients more prone to ischemia.

The management of acute stroke includes basic resuscitation, identifying type of stroke, and in case of ischemic stroke, administration of aspirin and if appropriate, fibrinolytic therapy or thrombectomy. General care in acute settings may include induced arterial hypertension, glycemic control, received

August 7, 2018

accepted after revision

September 5, 2018

published online

October 2, 2018
DOI https://doi.org/

10.1055/s-0038-1673549

ISSN 2348-0548.
Copyright $\odot 2018$ Indian Society of Neuroanaesthesiology and Critical Care
License terms

(이 (1) $\Theta \circledast$ 
Table 1 Risk factors and preventive measures for ischemic stroke $^{5-7,16,17}$

\begin{tabular}{|l|l|}
\hline Risk factors & Preventive measures \\
\hline Age $>60$ years & - \\
\hline Male gender & - \\
\hline Pregnancy & - \\
\hline Hypertension & Blood pressure control \\
\hline Obesity & Weight reduction \\
\hline Diabetes mellitus & Glycemic control \\
\hline Atrial fibrillation & $\begin{array}{l}\text { Active screening, oral } \\
\text { anticoagulants }\end{array}$ \\
\hline Valvular heart disease & Warfarin, surgery \\
\hline $\begin{array}{l}\text { Previous stroke or tran- } \\
\text { sient ischemic attack }\end{array}$ & $\begin{array}{l}\text { Carotid artery surgery/ } \\
\text { stenting }\end{array}$ \\
\hline Hyperlipidemia & $\begin{array}{l}\text { Treatment for dyslipidemia } \\
\text { and niacin }\end{array}$ \\
\hline Atherosclerosis & Antiplatelet drugs \\
\hline Carotid stenosis & $\begin{array}{l}\text { Carotid endarterectomy/endo- } \\
\text { vascular intervention }\end{array}$ \\
\hline Contraceptive pills & Avoidance \\
\hline Smoking & Cessation of smoking \\
\hline Drug and alcohol abuse & Reduction or elimination \\
\hline Sedentary lifestyle & Physical activity \\
\hline Diet & $\begin{array}{l}\text { Reduced salt and increased } \\
\text { potassium intake, diet rich in } \\
\text { fruits, nuts, and vegetables }\end{array}$ \\
\hline immobility & $\begin{array}{l}\text { Deep vein thrombosis } \\
\text { prophylaxis }\end{array}$ \\
\hline
\end{tabular}

maintaining normothermia, prevention of aspiration, and controlling seizures. ${ }^{7}$ All these measures are employed to either restore perfusion through occluded vessel or to enhance blood flow in the penumbra area to reduce the size of infarct.

After treatment and with the passage of time, limited degree of restoration of neurological function takes place. This neuronal plasticity may occur due to functional bi-hemispheric reorganization of cortical neurons following a stroke. ${ }^{14,15}$ Main factors that affect the level of recovery are severity of stroke, time elapsed after stroke, care given in acute phase, motivation, environment, and post-stroke rehabilitative training. A recurrent stroke in these patients is associated with poor outcome, and measures for secondary prevention should be employed ${ }^{5-7,16,17}$ (-Table1).

\section{Perioperative Concerns}

Perioperative problems in a patient with prior ischemic stroke include the following:

- Perioperative recurrence of stroke

- Re-emergence of neurological deficits postoperatively

- Anesthesia concerns related to prior stroke

- Problems related to concomitant diseases.
Perioperative stroke: The term "perioperative stroke" is defined as "A brain infarction of ischemic or hemorrhagic etiology that occurs during surgery or within 30 days after surgery."18 Perioperative strokes are predominantly either ischemic or embolic in origin. Anesthesia and surgery may cause perturbations in cardiac output, cerebral metabolism, and oxygenation leading to precipitation of perioperative recurrent stroke. ${ }^{5,19}$ A hypercoagulable state caused by surgical trauma and postoperative immobility and withdrawal of antiplatelet agents further make a patient with a prior stroke potentially "at higher risk" of recurring ischemic brain injury after surgery. $5,16,17,20$ The risk of postoperative stroke or transient ischemic attack (TIA) is maximum at 1 to 3 days after surgery (risk ratio: 34.0 ) but remains increased till 90 days after the surgery. ${ }^{21}$

History of a prior stroke is the most consistent risk factor of perioperative stroke. ${ }^{18}$ The incidence reported with noncardiac, non-major vascular surgery is approximately 2 to $3 \%$ in patients with prior stroke or TIA as against 0.1 to $2.3 \%$ overall. ${ }^{4,19,22-24}$ Reported incidences of perioperative stroke are the highest with cardiac (4.6-27.6\%) and carotid surgeries (5.6\%). ${ }^{25-27}$ Hip arthroplasty and head and neck surgeries have higher incidence of stroke than knee or general surgeries. ${ }^{16,17,28,29}$ Exposure to anesthesia and surgery has been found to be an independent risk factor for producing stroke even after non-high-risk surgeries. ${ }^{28,30}$ Perioperative stroke also carries approximately eightfold increase in risk of mortality as compared with patients without stroke. ${ }^{31}$ The reported mortality is as high as $60 \%$ in patients with a history of prior stroke. ${ }^{19,21,24,31-33}$ Patients with a history of TIA often have silent infarcts and also have similar risk of perioperative stroke. ${ }^{34,35}$ The Society for Neuroscience in Anesthesiology and Critical Care (SNACC) has released recommendations for care of patients who are at high risk of perioperative stroke during noncardiac, non-neurologic surgery. ${ }^{18}$

Re-emergence of neurological deficits: Ischemic stroke patients who had suffered from hemiplegia or major neurological deficits and have recovered significantly over time can again show re-emergence of previous neurological deficits after exposure to benzodiazepines, opioids, or after general anesthesia (GA). ${ }^{36-40}$ This phenomenon is transient and recovers in short time. It indicates that the injured part of brain is sensitive, and the compensatory neural networks may remain susceptible for a long time after functional recovery. ${ }^{38}$ Drug-induced reduction in cerebral perfusion in the "penumbra area" is considered contributory to these neurological deficits. ${ }^{41}$ Possible role for gamma-Aminobutyric acid (GABA)-mediated neurochemical mechanisms for both poststroke improvement and sensitivity to benzodiazepines is also suggested. ${ }^{37}$ Similar findings have been noted in patients with previous TIA. ${ }^{42,43}$ Exacerbation of prior unrecognized or unreported neurological deficits has been reported following spinal/epidural anesthesia. ${ }^{44}$

Anesthesia concerns related to prior stroke: Main perioperative concerns are related to either the prior stroke and prolonged debility with its sequelae or with other associated co-morbidities. Major cerebrovascular accident patients 
with prolonged immobility may have increased risk of aspiration due to impaired swallowing, ineffective cough and reduced gastric emptying, deep venous thrombosis, and pulmonary embolism. They often have poor nutritional intake leading to electrolyte disturbances, hypoproteinemia, and increased sensitivity to anesthesia drugs. ${ }^{45}$ Co-existing coronary artery disease, reduced cardiac or renal function, hypertension, diabetes, and chronic obstructive pulmonary disease with concomitant drug therapy pose individual challenges.

\section{Preoperative Assessment and Optimization}

The main considerations in these patients are to identify patients at risk and favorably alter modifiable risk factors to limit their impact on outcome. Patients with prior stroke should be thoroughly evaluated for their cerebrovascular status and other sources of perioperative morbidity.

Assessment of neurological deficit and recovery in function: This involves detailed questioning about current disability. Extent of neurological dysfunction and its recovery after acute stroke should be noted. A full functional recovery from previous stroke in a patient indicates restoration of blood supply to a major extent than in a patient with persistent deficit. Symptoms such as memory lapses, altered emotional behavior, or inability to express may be positive indicators of previous undiagnosed stroke. ${ }^{44}$ All the findings must be documented.

Stroke-related diagnostic tests such as carotid Doppler and magnetic resonance angiography, are important in cases of recent, symptomatic strokes to evaluate and discuss with surgeons and neurologists the plan of optimization before elective surgery. ${ }^{3,5}$ In patients with recent history of TIA, magnetic resonance imaging may detect silent infarcts.

Risk of perioperative stroke or aggravation of neurological symptoms should be discussed preoperatively with the patient, and informed consent should be obtained. ${ }^{18}$

Time elapsed since stroke and timing of elective surgery: The issue of optimal timing for an elective surgery in a patient with recent ischemic stroke is inadequately studied. For carotid endarterectomy (CEA), many studies recommended waiting for at least 4 to 6 weeks to reduce perioperative risk of complications. ${ }^{46,47}$ However, more recent studies have found reduced risk of second stroke with no difference in perioperative complications after early CEA within 1 to 2 weeks. ${ }^{48-50}$

Jørgensen et al investigated the association between prior stroke and the risk of major adverse cardiovascular events (MACE) in a large cohort of 481,183 noncardiac elective surgeries of which 7,137 surgeries were performed in patients with a history of stroke. ${ }^{22}$ They reported a higher risk of perioperative stroke (odds ratio [OR]: $67.60,95 \%$ confidence interval $[\mathrm{CI}]: 52.27-87.42$ ) in patients who had prior stroke within 3 months before surgery. Later, as the time passes, the risk reduces, and after 9 months of an ischemic stroke, the risks remained same as for those who did not have prior stroke. ${ }^{22}$ Perioperative stroke risk was seen equally in patients who underwent higher or medium-/low-risk surgeries. They also noted 4.8- and 1.8-fold increased relative risk of 30-day MACE and mortality, respectively. ${ }^{22}$ For an emergency surgery, there is always a compromise between the cerebrovascular vulnerability and treatment of current surgical pathology. Christiansen et al studied the association between time elapsed after ischemic stroke and risk of adverse events after emergency noncardiac surgery. A total of 146,694 emergency surgeries with 7,861 patients (5.4\%) having previous stroke were studied, and a risk of MACE (OR: 4.71) was reported..$^{51}$ Overall the evidence suggests that it would be safer to consider delaying an elective surgery for 3 to 9 months after an acute ischemic stroke to reduce the risk of secondary perioperative cerebrovascular event. 5,16,18,19,32,52

Treatment received during acute phase: Medical and surgical interventions received during acute phase should be noted. A patient who has been thrombolyzed or undergone mechanical thrombectomy immediately after stroke is likely to have a patent vessel with smaller infarct along with good functional recovery. The patient may have undergone carotid artery revascularization surgery for long-term prevention of stroke.

Performing a carotid artery revascularization surgery before an elective surgery is generally unwarranted after 12 weeks of stroke as then the risks of the procedure outweigh any stroke risk reduction benefit. $5,17,35,53$ Only symptomatic patients with bilateral significant carotid stenosis may benefit with carotid revascularization before major elective surgery. ${ }^{17}$ Therefore, need for CEA or stenting before elective noncardiac and nonvascular surgery should be individualized after discussion with neurologist and surgeon.

Associated systemic conditions: All major systems should be evaluated to identify co-existing illnesses. Presence and severity of ischemic heart disease, prior myocardial infarction, and its current implications need to be ascertained. Systolic dysfunction and presence of atrial dysfunction increase the risk of perioperative stroke and should be treated before elective surgery. ${ }^{5,17}$ Diabetes, hypertension, chronic renal insufficiency, and chronic obstructive pulmonary disease are common and should be optimized preoperatively. In chronic debilitated patients, presence of pulmonary aspiration, pneumonitis, and deep venous thrombosis should be looked for and treated. Nutritional and electrolyte status must be assessed and corrected.

Assessment of current surgical condition: Patients with prior stroke often present for cardiac, general surgical, cancer, or cataract surgery. Hip fractures are also a common complication after stroke. ${ }^{54}$ Magnitude, invasiveness, hemodynamic perturbations, and urgency of proposed surgery should be individually assessed, and the baseline investigations such as complete blood count, basic liver and renal function tests, serum electrolytes, coagulation profile, electrocardiogram, and chest X-ray are to be considered. Additional investigations are done as per the need of surgery and associated conditions.

Current medications: Often stroke patients are on antihypertensive and long-term prophylactic antiplatelet agents. Antihypertensive medications and statins should be continued preoperatively, and adequate hydration should be ensured. ${ }^{55}$ Statins if started 2 weeks prior to 
surgery reduce incidence of perioperative cardiac events and stroke, whereas perioperative withdrawal of statins is associated with increased risk. ${ }^{56,57}$ Ongoing $\beta$-blockers should be continued..$^{58}$ As intraoperative metoprolol is associated with a 3.3-fold increased risk of perioperative stroke, other $\beta$-blockers such as esmolol or labetalol are recommended for intraoperative reduction of heart rate. ${ }^{20}$

The American Heart Association stroke prevention guidelines recommend aspirin alone or in combination with clopidogrel for 21 to 90 days for secondary stroke prevention. ${ }^{8}$ When these patients present for surgery, continuation of aspirin increases the risk of major bleeding, without any benefit in reducing the risk of stroke. ${ }^{59}$ Withholding the drug for 7 days does not increase thrombotic risk, ${ }^{59}$ but discontinuation for 2 weeks significantly increased risk of a major ischemic event. ${ }^{16,60,61}$ Hence, aspirin in low dose (75 mg) can be safely continued for many surgeries where low risk of bleeding is involved $^{61,62}$ and should be discontinued for short periods for surgeries having higher risk of bleeding or hematoma such as intracranial, middle ear, posterior chamber of eye, major spine, and possibly transurethral prostate surgery. ${ }^{60}$ Sudden withdrawal of aspirin can trigger rebound hypercoagulable state, particularly in coronary artery disease patients or in a chronically bed-ridden patient, increasing the risk of a perioperative cerebral thrombotic event, ${ }^{5,60,63}$ but another study has found no such increase ${ }^{59}$ Clopidogrel is associated with higher risk of intraoperative bleeding; hence, it should be stopped at least 5 to 7 days prior to surgery. ${ }^{5,64,65}$ If patient is on anticoagulants, bridging therapy with intravenous unfractionated heparin should be considered. An individual risk-benefit assessment evaluating risk of bleeding versus thrombosis must be done, and the drugs should be resumed as soon as risk of surgical bleeding reduces. ${ }^{5,66}$

Preoperative sedation: Sedative premedicants are either avoided or if given, used in minimal dosages in a monitored area, as these patients are likely to be more sensitive to sedative drugs.

\section{Anesthesia Considerations}

Anesthesia considerations differ according to the surgery proposed. Different techniques of anesthesia are associated with alterations in blood pressure, levels of oxygen, carbon dioxide, and blood glucose, which can have adverse effects on brain.

Intraoperative monitoring: Apart from the standard monitoring such as electrocardiogram, pulse oximetry, capnography, and blood pressure monitoring, additional monitors may be needed as per the patient's condition and the surgical procedure planned and its urgency. Invasive arterial blood pressure, central venous pressure, and urine output should be monitored in all major cases to ensure stable hemodynamics and to judge adequacy of circulatory volume. Neuromuscular junction monitoring should be done on the unaffected side. ${ }^{67}$ Cerebral electrophysiological monitoring and transcranial Doppler (TCD) are restricted to patients at high-risk repeat stroke. ${ }^{68}$ As cerebral perfusion correlates better with cardiac output and cardiac index in stroke patients, cardiac output-based management may be used in patients at high risk. ${ }^{69}$ Cerebral oximetry is useful to detect ischemia during high-risk cardiac or major vascular surgery and surgeries in beach chair position. ${ }^{68,70,71}$

Techniques of anesthesia and surgery: Few studies have compared GA versus regional anesthesia (RA) techniques in stroke patients to evaluate perioperative complications. Most of them have studied patients undergoing carotid artery surgery. For CEA, earlier reports showed insignificant advantage of RA over GA in reducing perioperative stroke and death incidence. ${ }^{47}$ However, later studies have proven that GA does not increase the risk of perioperative stroke during CEA. ${ }^{72}$ For other types of surgeries, there is insufficient evidence about advantages of one technique over the other. Two studies have reported that GA is associated with higher incidence of perioperative cerebrovascular events than RA in orthopedic surgery. ${ }^{30,73}$ However, these studies did not specify how many patients with prior cerebrovascular disease developed perioperative complications. The selection of the surgical technique-open versus minimally invasive-as per the patient's risk profile is also important. ${ }^{17}$ Surgery duration should also be minimized as long duration surgeries are associated with higher risks for perioperative complications and stroke. ${ }^{17}$

Anesthesia drugs: Among the general anesthetics, intravenous anesthetic agents reduce cerebral metabolism and can thus offer cerebral protection. Inhalational agents are vasodilators and therefore may be beneficial. ${ }^{68}$ Addition of intermediate- or short-acting opioids reduces the dose of induction agents and thereby reducing hemodynamic instability during induction. However, there are insufficient data available to consider a specific agent to be more neuroprotective. Exposure to nitrous oxide has not demonstrated an increased risk of stroke in patients undergoing carotid artery surgery or major non-cardiac surgery. ${ }^{74,75}$ Succinylcholine should be avoided in stroke patients with significant loss of muscle function for fear of life-threatening hyperkalemia. Commonly used cardio-stable non-depolarizing neuromuscular blocking agents can be safely used. Maintenance of anesthesia can be done with either inhalational agents or propofol if stable hemodynamics are achieved. With either technique, one should aim for smooth and rapid emergence for early postoperative neurological assessment. High doses of anesthetic agents to provide cerebral protection are not employed routinely as they are associated with hemodynamic fluctuations. Dexmedetomidine and propofol have been found to be safe in acute stroke victims for endovascular surgeries, but dexmedetomidine is associated with more hemodynamic changes and must be used with caution. ${ }^{76,77}$

Blood pressure management: As most patients with prior ischemic stroke have some reduction in focal cerebral blood flow, hypotension may further reduce it. Though some studies associate intraoperative hypotension with worsened outcome, there are insufficient data to prove impact of it causing recurrent stroke. ${ }^{19,78}$ It may be predictive of postoperative hypotension which may not be identified readily in less monitored surroundings, putting the patient at risk of postoperative stroke. ${ }^{18,79}$ 
The baseline blood pressure should be ascertained, and intraoperative blood pressure should be maintained at baseline or slightly elevated levels. Significant interperson variations exist in lower limit of cerebral autoregulation, and caution is advised. ${ }^{80}$ Deliberate hypotension must be avoided. Vasopressors may be needed to maintain blood pressure. However, incidence of myocardial ischemia is higher with use of phenylephrine or metaraminol. ${ }^{81}$ In case of carotid artery surgery, a deliberate intraoperative increase in blood pressure has been advocated. ${ }^{80}$ For surgeries done in upright or beach chair position, location of blood pressure cuff should be on the arm, and blood pressure gradient between the brachial artery and brain should be taken into consideration; adjustments are needed to judge adequacy of cerebral perfusion to avoid ischemic neurological injuries. ${ }^{18,82}$ In upright position surgery, if invasive blood pressure is monitored, transducer should be zeroed at the level of forehead to monitor cerebral blood flow. ${ }^{18}$

Oxygenation and ventilation: Intraoperative hypoxia and cerebral edema reduce perfusion to the penumbra area and may extend the ischemic damage to adjacent areas. ${ }^{83}$ Partial pressures of carbon dioxide $\left(\mathrm{PaCO}_{2}\right)$ should be maintained close to the baseline levels. If baseline preoperative values are not known in case of absence of preoperative blood gases, ventilation should be adjusted to normalize the blood $\mathrm{pH}$. Hyperventilation should be avoided as resultant hypocarbia reduces the cerebral blood flow which is undesirable in patients who are at potential risk for perioperative stroke. ${ }^{18}$ Patients with chronic large artery ischemic infarcts show significantly lower augmentation of cerebral blood flow with an increase in $\mathrm{PaCO}_{2}$, but develop greater reduction in blood flow with a decrease in $\mathrm{PaCO}_{2}{ }^{12,80}$ Hypercarbia should be promptly corrected because it can induce "steal" phenomenon and reduce blood flow to the vulnerable ischemic areas of brain as vasoreactivity on the nonstroke side is less affected. ${ }^{12}$

Blood transfusion: Though there is no consensus at which level hemoglobin should be maintained, both polycythemia (by reducing tissue perfusion) and anemia (by reducing oxygen carrying capacity) are likely be detrimental. It is preferable to keep the transfusion trigger to a higher level (above $9.0 \mathrm{~g} / \mathrm{dL}$ ) in patient with a prior stroke than in a healthy patient..$^{18}$ Delay in blood replacement increases the risk of repeat stroke as well as makes the patient prone to intraoperative myocardial ischemia in presence of associated coronary artery disease. There is evidence that anemia may induce cerebral injury and stroke possibly due to decreased oxygen-carrying capacity. ${ }^{84,85}$ Lower hemoglobin levels are associated with larger strokes and infarct growth. ${ }^{86}$

Glucose management: Brain is dependent on continuous supply of glucose for its function, and hypoglycemia should be strictly avoided. Hyperglycemia on the other hand aggravates severity of cerebral ischemia or hypoxia if such events happen. Intensive intraoperative insulin therapy has been associated with an increased risk of stroke and death after cardiac surgery ${ }^{87}$ and higher incidence of hypoglycemia after acute stroke. ${ }^{88}$ Lower glucose levels in acute phase of stroke are associated with worse cognitive outcome. ${ }^{89}$ It is recommended to keep blood glucose levels in range of 60 to $180 \mathrm{mg} / \mathrm{dL}$ in patients at high risk for perioperative stroke. ${ }^{18}$

Supportive measures: Anti-aspiration prophylaxis should be provided in view of possibility of delayed gastric emptying or impaired protective airway reflexes. Normothermia should be maintained. Inflammation and infection, as indicated by high leukocyte count, are associated with higher risk of perioperative stroke and therefore should be prevented or promptly treated. ${ }^{17}$ Corticosteroids are not indicated.

Recovery from anesthesia: Recovery of protective airway reflexes should be ascertained while considering tracheal extubation. An ischemic brain may respond differently to anesthetic agents than a normal brain. Immediately on awakening from anesthesia, short-term unilateral delayed return of motor function has been noted on the affected side. This phenomenon has been termed as "differential awakening." 40 Therefore, on recovery from anesthesia, neurological function should be assessed at the earliest. If any new motor deficits are noted, the patient needs to be closely monitored, and if deficits persist, radiological testing may be needed.

\section{Postoperative Care}

Patients with severe neurological deficit or after major surgery should be monitored in high-dependency unit. Postoperative electrolyte imbalance and shifts in the intravascular volume can predispose the patient to arrhythmias. ${ }^{17}$ Patients should be closely monitored for volume and electrolyte status, cardiac arrhythmia, systolic dysfunction, and infections. Prophylactic measures should be taken to prevent deep venous thrombosis, and if the patient was receiving anticoagulant or antiplatelet therapy preoperatively, it should be restarted as early as possible.

\section{Cardiac Surgery}

Cardiac surgery in a patient with previous stroke is common due to occurrence of both coronary and carotid diseases simultaneously. Cardiac surgery is associated with higher risk of cerebral complications-perioperative stroke, delayed recovery, and delayed extubation..$^{25,27}$ Optimal cardiopulmonary performance and hemoglobin concentration should be maintained. Intraoperative neuromonitoring such as cerebral electrophysiological monitoring, cerebral oximetry, and TCD, helps to monitor cerebral function, oxygenation, and flow through major vessels, but its utility and efficacy for tailoring the anesthetic management are yet to be ascertained. ${ }^{68}$ One must ensure adequate delivery of oxygen-rich blood to brain at all the times, especially during the cardiopulmonary bypass. If postoperative atrial fibrillation is present, heparin therapy should be started and be continued for 30 days after the return of normal sinus rhythm. ${ }^{90}$

\section{Past Hemorrhagic Stroke and Anesthesia}

Intracranial hemorrhage may occur primarily due to spontaneous rupture of intracranial small arteries with hypertension or amyloid angiopathy or secondary to trauma, aneurysm 
rupture, arteriovenous malformation, or as a complication of venous infarct. ${ }^{91}$ It may be associated with the use of anticoagulant drugs. Patients with primary intracranial hemorrhage have a $1.67 \%$ annual average incidence of first recurrence. Cumulative incidence of recurrence rates at 5 and 10 years is $9.6 \%$ and $14.2 \%$, respectively. ${ }^{92}$ The average annual recurrence rate is higher in those with previous ischemic stroke than in those without (3.52\% vs. $1.35 \%$ ). ${ }^{92}$ However, currently there is no evidence that prior intracranial hemorrhage patients are at higher risk of developing complications perioperatively if the original cause for hemorrhage has been treated. However, it seems prudent to avoid acute increases in blood pressure in perioperative period to prevent a recurrence. The anesthesia technique depends upon the presence and severity of other co-existing diseases and the surgical procedure.

\section{Conclusion}

In conclusion, a history of prior stroke potentially puts the patients at high risk of perioperative stroke and neurological deficits. To reduce the risk, one should optimize the patient by improving the modifiable factors. Timing of surgery should be decided after carefully judging risk-benefit ratio. Careful titration of anesthesia and close monitoring extending till several days postoperatively are needed.

\section{Conflict of Interest}

None.

\section{References}

1 Feigin VL, Norrving B, Mensah GA. Global burden of stroke. Circ Res 2017;120(3):439-448

2 Krishnamurthi RV, Moran AE, Feigin VL, et al; GBD 2013 Stroke Panel Experts Group. Stroke prevalence, mortality and disability-adjusted life years in adults aged 20-64 Years in 1990-2013: data from the global burden of disease 2013 study. Neuroepidemiology 2015;45(3):190-202

3 Logvinova AV, Litt L, Young WL, Lee CZ. Anesthetic concerns in patients with known cerebrovascular insufficiency. Anesthesiol Clin 2010;28(1):1-12

4 Kim J, Gelb AW. Predicting perioperative stroke. J Neurosurg Anesthesiol 1995;7(3):211-215

5 Mehdi Z, Birns J, Partridge J, Bhalla A, Dhesi J. Perioperative management of adult patients with a history of stroke or transient ischaemic attack undergoing elective non-cardiac surgery. Clin Med (Lond) 2016;16(6):535-540 (Northfield Il)

6 McCrary MR, Song W, Ling W. Ischemic stroke mechanisms, prevention, and treatment: the anesthesiologist's perspective. J Anesth Perioper Med 2017;4:76-86

7 Meschia JF, Bushnell C, Boden-Albala B, et al; American Heart Association Stroke Council; Council on Cardiovascular and Stroke Nursing; Council on Clinical Cardiology; Council on Functional Genomics and Translational Biology; Council on Hypertension. Guidelines for the primary prevention of stroke: a statement for healthcare professionals from the American Heart Association/American Stroke Association. Stroke 2014;45(12):3754-3832

8 Kernan WN, Ovbiagele B, Black HR, et al; American Heart Association Stroke Council, Council on Cardiovascular and Stroke Nursing, Council on Clinical Cardiology, and Council on Peripheral Vascular Disease. Guidelines for the prevention of stroke in patients with stroke and transient ischemic attack: a guideline for healthcare professionals from the American
Heart Association/American Stroke Association. Stroke 2014;45(7):2160-2236

9 Aries MJ, Elting JW, De Keyser J, Kremer BP, Vroomen PC. Cerebral autoregulation in stroke: a review of transcranial Doppler studies. Stroke 2010;41(11):2697-2704

10 Dawson SL, Blake MJ, Panerai RB, Potter JF. Dynamic but not static cerebral autoregulation is impaired in acute ischaemic stroke. Cerebrovasc Dis 2000;10(2):126-132

11 Reinhard M, Roth M, Guschlbauer B, et al. Dynamic cerebral autoregulation in acute ischemic stroke assessed from spontaneous blood pressure fluctuations. Stroke 2005;36(8):1684-1689

12 Zhao P, Alsop DC, Abduljalil A, et al. Vasoreactivity and peri-infarct hyperintensities in stroke. Neurology 2009; 72(7):643-649

13 Gommer ED, Staals J, van Oostenbrugge RJ, Lodder J, Mess WH, Reulen JP. Dynamic cerebral autoregulation and cerebrovascular reactivity: a comparative study in lacunar infarct patients. Physiol Meas 2008;29(11):1293-1303

14 Nudo RJ. Postinfarct cortical plasticity and behavioral recovery. Stroke $2007 ; 38(2$, Suppl) :840-845

15 Takeuchi N, Izumi S. Maladaptive plasticity for motor recovery after stroke: mechanisms and approaches. Neural Plast 2012;2012:359728

$16 \mathrm{Ng} \mathrm{JL}$, Chan MT, Gelb AW. Perioperative stroke in noncardiac, nonneurosurgical surgery. Anesthesiology 2011; 115(4):879-890

17 Selim M. Perioperative stroke. N Engl J Med 2007;356(7): 706-713

18 Mashour GA, Moore LE, Lele AV, Robicsek SA, Gelb AW. Perioperative care of patients at high risk for stroke during or after non-cardiac, non-neurologic surgery: consensus statement from the Society for Neuroscience in Anesthesiology and Critical Care. J Neurosurg Anesthesiol 2014;26(4):273-285

19 Landercasper J, Merz BJ, Cogbill TH, et al. Perioperative stroke risk in 173 consecutive patients with a past history of stroke. Arch Surg 1990;125(8):986-989

20 Mashour GA, Sharifpour M, Freundlich RE, et al. Perioperative metoprolol and risk of stroke after noncardiac surgery. Anesthesiology 2013;119(6):1340-1346

21 Grau AJ, Eicke M, Burmeister C, Hardt R, Schmitt E, Dienlin S. Risk of ischemic stroke and transient ischemic attack is increased up to 90 days after non-carotid and non-cardiac surgery. Cerebrovasc Dis 2017;43(5-6):242-249

22 Jørgensen ME, Torp-Pedersen C, Gislason GH, et al. Time elapsed after ischemic stroke and risk of adverse cardiovascular events and mortality following elective noncardiac surgery. JAMA 2014;312(3):269-277

23 Biteker M, Kayatas K, Türkmen FM, Misırlı CH. Impact of perioperative acute ischemic stroke on the outcomes of noncardiac and nonvascular surgery: a single centre prospective study. Can J Surg 2014;57(3):E55-E61

24 Sanders RD, Jørgensen ME, Mashour GA. Perioperative stroke: a question of timing? Br J Anaesth 2015;115(1):11-13

25 Bucerius J, Gummert JF, Borger MA, et al. Stroke after cardiac surgery: a risk factor analysis of 16,184 consecutive adult patients. Ann Thorac Surg 2003;75(2):472-478

26 Maatz W, Köhler J, Botsios S, John V, Walterbusch G. Risk of stroke for carotid endarterectomy patients with contralateral carotid occlusion. Ann Vasc Surg 2008;22(1):45-51

27 Chiao SS, Zuo ZY. Approach to risk management of perioperative stroke. J Anesth Perioper Med 2015;2:268-276

28 Wong GY, Warner DO, Schroeder DR, et al. Risk of surgery and anesthesia for ischemic stroke. Anesthesiology 2000;92(2):425-432

29 Bateman BT, Schumacher HC, Wang S, Shaefi S, Berman MF. Perioperative acute ischemic stroke in noncardiac and nonvascular surgery: incidence, risk factors, and outcomes. Anesthesiology 2009;110(2):231-238 
30 Mortazavi SM, Kakli H, Bican O, Moussouttas M, Parvizi J, Rothman RH. Perioperative stroke after total joint arthroplasty: prevalence, predictors, and outcome. J Bone Joint Surg Am 2010;92(11):2095-2101

31 Mashour GA, Shanks AM, Kheterpal S. Perioperative stroke and associated mortality after noncardiac, nonneurologic surgery. Anesthesiology 2011;114(6):1289-1296

32 Pasternak JJ, Lanier WL. Diseases affecting the brain. In: Hines RL, Marschall KE, eds. Stoelting's Anesthesia and Co-Existing Disease. 7th ed. Philadelphia: Elsevier Inc.; 2018:218-254

33 Parikh S, Cohen JR. Perioperative stroke after general surgical procedures. N Y State J Med 1993;93(3):162-165

34 Herderscheê D, Hijdra A, Algra A, Koudstaal PJ, Kappelle LJ, van Gijn J; The Dutch TIA Trial Study Group. Silent stroke in patients with transient ischemic attack or minor ischemic stroke. Stroke 1992;23(9):1220-1224

35 Streifler JY, den Hartog AG, Pan S, et al; ACST-1 trial collaborators. Ten-year risk of stroke in patients with previous cerebral infarction and the impact of carotid surgery in the Asymptomatic Carotid Surgery Trial. Int J Stroke 2016;11(9):1020-1027

36 Thal GD, Szabo MD, Lopez-Bresnahan M, Crosby G. Exacerbation or unmasking of focal neurologic deficits by sedatives. Anesthesiology 1996;85(1):21-25, discussion 29A-30A

37 Lazar RM, Fitzsimmons BF, Marshall RS, et al Reemergence of stroke deficits with midazolam challenge. Stroke 2002; 33(1):283-285

38 Bernstock JD, Budinich CS, Cohen LG, Awosika OO. Recrudescence of focal stroke symptoms during pain management with hydromorphone. Front Neurol 2016;7:50

39 Topcuoglu MA, Saka E, Silverman SB, Schwamm LH, Singhal AB. Recrudescence of deficits after stroke: Clinical and imaging phenotype, triggers, and risk factors. JAMA Neurol 2017;74(9):1048-1055

40 Cucchiara RF. Differential awakening. Anesth Analg 1992; 75(3):467

41 Matthew E, Andreason P, Pettigrew K, et al. Benzodiazepine receptors mediate regional blood flow changes in the living human brain. Proc Natl Acad Sci U S A 1995;92(7):2775-2779

42 Lazar RM, Fitzsimmons BF, Marshall RS, Mohr JP, Berman MF. Midazolam challenge reinduces neurological deficits after transient ischemic attack. Stroke 2003;34(3):794-796

43 Pang W, Lin RM, Lin M, et al. Midazolam-induced unexpected monoparesis : not contraindicated for ambulatory general anesthesia. Ambul Surg 2018;24:12-14

44 Aldrete JA, Reza-Medina M, Daud O, et al. Exacerbation of preexisting neurological deficits by neuraxial anesthesia: report of 7 cases. J Clin Anesth 2005;17(4):304-313

45 Veenith TV, Din AH, Eaton DM, Burnstein RM. Perioperative care of a patient with stroke. Int Arch Med 2010;3:33

46 Keldahl ML, Eskandari MK. Timing of carotid surgery after acute stroke. Expert Rev Cardiovasc Ther 2010; 8(10):1399-1403

47 Rockman CB, Maldonado TS, Jacobowitz GR, Cayne NS, Gagne PJ, Riles TS. Early carotid endarterectomy in symptomatic patients is associated with poorer perioperative outcomes. J Vasc Surg 2006;44(3):480-487

48 Annambhotla S, Park MS, Keldahl ML, et al. Early versus delayed carotid endarterectomy in symptomatic patients. J Vasc Surg 2012;56(5):1296-1302, discussion 1302

49 Liu H, Chu J, Zhang L, Liu C, Yan Z, Zhou S. Clinical comparison of outcomes of early versus delayed carotid artery stenting for symptomatic cerebral watershed infarction due to stenosis of the proximal internal carotid artery. BioMed Res Int 2016;2016:6241546

50 Koraen-Smith L, Troëng T, Björck M, Kragsterman B, Wahlgren CM; Swedish Vascular Registry and the
Riks-Stroke Collaboration. Urgent carotid surgery and stenting may be safe after systemic thrombolysis for stroke. Stroke 2014;45(3):776-780

51 Christiansen MN, Andersson C, Gislason GH, et al. Risks of cardiovascular adverse events and death in patients with previous stroke undergoing emergency noncardiac, nonintracranial surgery: the importance of operative timing. Anesthesiology 2017;127(1):9-19

52 Blacker DJ, Flemming KD, Link MJ, Brown RD Jr. The preoperative cerebrovascular consultation: common cerebrovascular questions before general or cardiac surgery. Mayo Clin Proc 2004;79(2):223-229

53 Pini R, Faggioli G, Longhi M, et al. The detrimental impact of silent cerebral infarcts on asymptomatic carotid endarterectomy outcome. J Vasc Surg 2016;64(1):15-24

54 Ramnemark A, Nyberg L, Borssén B, Olsson T, Gustafson Y. Fractures after stroke. Osteoporos Int 1998;8(1):92-95

55 Kristensen SD, Knuuti J, Saraste A, et al; Authors/Task Force Members. 2014 ESC/ESA Guidelines on non-cardiac surgery: cardiovascular assessment and management: the Joint Task Force on non-cardiac surgery: cardiovascular assessment and management of the European Society of Cardiology (ESC) and the European Society of Anaesthesiology (ESA) Eur Heart J 2014;35(35):2383-2431

56 Mills EJ, Wu P, Chong G, et al. Efficacy and safety of statin treatment for cardiovascular disease: a network meta-analysis of 170,255 patients from 76 randomized trials. QJM 2011;104(2):109-124

57 Fallouh N, Chopra V. Statin withdrawal after major noncardiac surgery: risks, consequences, and preventative strategies. J Hosp Med 2012;7(7):573-579

58 Wallace AW, Au S, Cason BA. Association of the pattern of use of perioperative $\beta$-blockade and postoperative mortality. Anesthesiology 2010;113(4):794-805

59 Devereaux PJ, Mrkobrada M, Sessler DI, et al; POISE-2 Investigators. Aspirin in patients undergoing noncardiac surgery. N Engl J Med 2014;370(16):1494-1503

60 Gerstein NS, Schulman PM, Gerstein WH, Petersen TR, Tawil I. Should more patients continue aspirin therapy perioperatively?: clinical impact of aspirin withdrawal syndrome. Ann Surg 2012;255(5):811-819

61 Burger W, Chemnitius JM, Kneissl GD, Rücker G. Low-dose aspirin for secondary cardiovascular prevention - cardiovascular risks after its perioperative withdrawal versus bleeding risks with its continuation - review and meta-analysis. J Intern Med 2005;257(5):399-414

62 Oscarsson A, Gupta A, Fredrikson M, et al. To continue or discontinue aspirin in the perioperative period: a randomized, controlled clinical trial. Br J Anaesth 2010;104(3):305-312

63 Maulaz AB, Bezerra DC, Michel P, Bogousslavsky J. Effect of discontinuing aspirin therapy on the risk of brain ischemic stroke. Arch Neurol 2005;62(8):1217-1220

64 Mehta SR, Yusuf S; Clopidogrel in Unstable angina to prevent Recurrent Events (CURE) Study Investigators. The Clopidogrel in Unstable angina to prevent Recurrent Events (CURE) trial programme; rationale, design and baseline characteristics including a meta-analysis of the effects of thienopyridines in vascular disease. Eur Heart J 2000;21(24):2033-2041

65 Douketis JD, Spyropoulos AC, Spencer FA, et al. Perioperative management of antithrombotic therapy. Antithrombotic therapy and prevention of thrombosis, 9th ed. American College of Chest Physicians evidence-based clinical practice guidelines. Chest 2012;141(2 suppl):e326S-e350S

66 Armstrong MJ, Gronseth G, Anderson DC, et al. Summary of evidence-based guideline: periprocedural management of antithrombotic medications in patients with ischemic cerebrovascular disease: report of the Guideline Development 
Subcommittee of the American Academy of Neurology. Neurology 2013;80(22):2065-2069

67 Müller R, Knüttgen D, Vorweg M, Doehn M. Neuromuscular monitoring in a patient with hemiparesis. Resistance of the paralysed musculature to non-depolarising muscle relaxants [German]. Anaesthesist 2002;51(8):644-649

68 Engelhard K. Anaesthetic techniques to prevent perioperative stroke. Curr Opin Anaesthesiol 2013;26(3):368-374

69 Fuhrer H, Reinhard M, Niesen WD. Paradigm change? Cardiac output better associates with cerebral perfusion than blood pressure in ischemic stroke. Front Neurol 2017;8:706

70 Gillespie R, Shishani Y, Streit J, et al. The safety of controlled hypotension for shoulder arthroscopy in the beach-chair position. J Bone Joint Surg Am 2012;94(14):1284-1290

71 Vohra HA, Modi A, Ohri SK. Does use of intra-operative cerebral regional oxygen saturation monitoring during cardiac surgery lead to improved clinical outcomes? Interact Cardiovasc Thorac Surg 2009;9(2):318-322

72 Lewis SC, Warlow CP, Bodenham AR, et al; GALA Trial Collaborative Group. General anaesthesia versus local anaesthesia for carotid surgery (GALA): a multicentre, randomised controlled trial. Lancet 2008;372(9656):2132-2142

73 Memtsoudis SG, Sun X, Chiu YL, et al. Perioperative comparative effectiveness of anesthetic technique in orthopedic patients. Anesthesiology 2013;118(5):1046-1058

74 Sanders RD, Graham C, Lewis SC, Bodenham A, Gough MJ, Warlow C; GALA Trial Investigators. Nitrous oxide exposure does not seem to be associated with increased mortality, stroke, and myocardial infarction: a non-randomized subgroup analysis of the General Anaesthesia compared with Local Anaesthesia for carotid surgery (GALA) trial. Br J Anaesth 2012;109(3):361-367

75 Myles PS, Leslie K, Chan MTV, et al; ANZCA Trials Group for the ENIGMA-II investigators. The safety of addition of nitrous oxide to general anaesthesia in at-risk patients having major non-cardiac surgery (ENIGMA-II): a randomised, single-blind trial. Lancet 2014;384(9952):1446-1454

76 Whalin MK, Lopian S, Wyatt K, et al. Dexmedetomidine: a safe alternative to general anesthesia for endovascular stroke treatment. J Neurointerv Surg 2014;6(4):270-275

77 John S, Somal J, Thebo U, et al. Safety and hemodynamic profile of propofol and dexmedetomidine anesthesia during intra-arterial acute stroke therapy. J Stroke Cerebrovasc Dis 2015;24(10):2397-2403

78 Treurniet KM, Berkhemer OA, Immink RV, et al; MR CLEAN investigators. A decrease in blood pressure is associated with unfavorable outcome in patients undergoing thrombectomy under general anesthesia. J Neurointerv Surg 2018;10(2):107-111
79 Bijker JB, Persoon S, Peelen LM, et al. Intraoperative hypotension and perioperative ischemic stroke after general surgery: a nested case-control study. Anesthesiology 2012;116(3):658-664

80 Meng L, Gelb AW. Regulation of cerebral autoregulation by carbon dioxide. Anesthesiology 2015;122(1):196-205

81 Smith JS, Roizen MF, Cahalan MK, et al. Does anesthetic technique make a difference? Augmentation of systolic blood pressure during carotid endarterectomy: effects of phenylephrine versus light anesthesia and of isoflurane versus halothane on the incidence of myocardial ischemia. Anesthesiology 1988;69(6):846-853

82 Cullen DJ, Kirby RR. Beach chair position may decrease cerebral perfusion: Catastrophic outcomes have occured. APSF Newsl 2007;22:25-27

83 Gelb AW, Cowie DA. Perioperative stroke prevention. Anesth Analg 2001;92:46-53

84 Hare GM, Tsui AK, McLaren AT, Ragoonanan TE, Yu J, Mazer $\mathrm{CD}$. Anemia and cerebral outcomes: many questions, fewer answers. Anesth Analg 2008;107(4):1356-1370

85 Giuffrida S, Carpinteri G, Modica D, et al. Focal neurological deficit in acute anemia: case reports and review of the literature. World J Neurosci 2013;3:53-56

86 Kimberly WT, Wu O, Arsava EM, et al. Lower hemoglobin correlates with larger stroke volumes in acute ischemic stroke. Cerebrovasc Dis Extra 2011;1(1):44-53

87 Gandhi GY, Nuttall GA, Abel MD, et al. Intensive intraoperative insulin therapy versus conventional glucose management during cardiac surgery: a randomized trial. Ann Intern Med 2007; 146(4):233-243

88 Bellolio MF, Gilmore RM, Ganti L. Insulin for glycaemic control in acute ischaemic stroke. Cochrane Database Syst Rev 2014;(1):CD005346

89 Zietemann V, Wollenweber FA, Bayer-Karpinska A, Biessels GJ, Dichgans M. Peripheral glucose levels and cognitive outcome after ischemic stroke-results from the Munich Stroke Cohort. Eur Stroke J 2016;1:51-60

90 Epstein AE, Alexander JC, Gutterman DD, Maisel W, Wharton JM; American College of Chest Physicians. Anticoagulation: American College of Chest Physicians guidelines for the prevention and management of postoperative atrial fibrillation after cardiac surgery. Chest 2005;128(2, Suppl)24S-27S

91 Fogarty Mack P. Intracranial haemorrhage: therapeutic interventions and anaesthetic management. Br J Anaesth 2014; 113(Suppl 2):ii17-ii25

92 Huhtakangas J, Löppönen P, Tetri S, et al. Predictors for recurrent primary intracerebral hemorrhage: a retrospective population-based study. Stroke 2013;44(3):585-590 